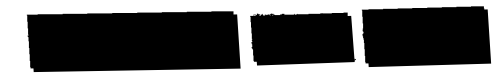

\title{
A DATABASE OF PFT VENTILATION MEASUREMENTS
}

Ted W. D'Ottavio, Robert W. Goodrich, Daniel J. Spandau, and Russell N. Dietz

August 1988

Prepared for VERSAR, INC.

6850 VERSAR CENTER

SPRINGFIELD, VIRGINIA 22151 


\section{A DATABASE OF PFT VENTILATION MEASUREMENTS}

Prepared by

Ted W. D'Ottavio, Robert W. Goodrich, Daniel J. Spandau, and Russell N. Dietz

August 1988

Prepared for

VERSAR, INC. 6850 VERSAR CENTER

SPRINGFIELD, VIRGINIA 22151
ENVIRONMENTAL CHEMISTRY DIVISION DEPARTMENT OF APPLIED SCIENCE BROOKHAVEN NATIONAL LABORATORY ASSOCIATED UNIVERSITIES, INC.

Under Contract No. DE-AC02-76CH00016 with the U.S. Department of Energy 
Thie report was prepared as an account of work sponsored by an agency of the United States Government. Neither the United States Government nor any agency thereof, nor any of their employees, nor any of their contractors, subcontractors, or their employees, makes any warranty, express or implied, or assumes any legal liability or responsibility for the accuracy, completeness, or usefulness of any information, apparatus, product, or process disclosed, or represents that its use would not infringe privately owned rights. Reference herein to any specific commercial product, process, or service by trade name, trademark, manufacturer, or otherwise, does not necessarily constitute or imply its endorsement, recommendation, or favoring by the United States Government or any agency, contractor or subcontractor thereof. The views and opinions of authors expressed herein do not necessarily state or reflect those of the United States Government or any agency, contractor or subcontractor thereof.

Printed in the United States of America

Available from

National Technical Information Service

U.S. Department of Commerce

5285 Port Royal Road

Springfield, VA 22161

NTIS price codes:

Printed Copy: A08; Microfiche Copy: A01 


\section{Introduction and Summary}

About five years ago, a method for measuring the ventilation flows of a building was developed at Brookhaven National Laboratory (BNL). This method is based on the use of a family of compounds known as perfluorocarbon tracers or PFTs. Since 1982, BNL has measured ventilation in more than 4000 homes, comprising about 100 separate research projects throughout the world. This measurement set is unique in that it is the only set of ventilation measurements that acknowledge and measure the multi-zone characteristics of residences. Other large measurement sets assume that a home can be treated as a single wellmixed zone.

This report describes the creation of a database of approximately half of the PFT ventilation measurements made by BNL over the last five years. A second phase of this project, to be completed over the next year, will add the second half of the measurements to the database. This work was supported by the Environmental Protection Agency (EPA) through a subcontract from Versar, Inc., parent company of GEOMET Technologies, Inc.

GEOMET, with funding from EPA, is currently involved in a longterm project which is attempting to mathematically model the release and transport in residential buildings of indoor air pollutants. Their need to describe the flow patterns within various types of residential structures at different times of the year and at different geographic locations has resulted in the work described in this report.

The PFT database is currently available for use on any IBM PC or Apple Macintosh based personal computer system. In addition to its utility in modeling indoor pollutant dispersion, this database may also be useful to those people studying energy conservation, thermal comfort and heating system design in residential buildings. 


\section{The PFT Ventilation Measurement System}

BNL staff developed and performed preliminary studies of a new passive PFT source and sampler system for the determination of air infiltration rates in homes and buildings between 1979 and 1982. The first measurements showing the feasibility of the PFT technology for measuring ventilation in buildings were performed in a two-story home in November 1979 and the first paper on the concept was presented in October 1981.

With the spin-off of a new research effort sponsored by the Department of Energy in 1982, the basic parts of the current measurement system, the tracer emission source and passive sampling system, were developed and used for the first time in a two-zone (first floor-second floor) study of the Brookhaven House, a solar energy research house located at BNL. By 1984, a family of four PFT source types were produced and calibrated and the PFT ventilation technique had been applied world-wide, from Alaska and Greenland to New Zealand. Since then, this technique has received world-wide recognition and has been commercialized and offered as a routine service through the National Association of Home Builders Research Foundation.

The PFT multizone ventilation measurement technique is an offshoot of the constant emission, steady state method of measuring air infiltration that has been around for many years. In that scheme, a tracer is emitted into a building at a constant rate and its concentration is allowed to reach a steady state level. This value is measured and then converted to a flow of outdoor air into the building through the use of a single zone, mass balance model.

At BNL, we have extended this method to multizone ventilation measurements by using multiple perfluorocarbon tracers (PFTs), one of which is emitted in each well-mixed zone of a building. Measurement of the concentrations of each tracer in all zones of the building permits the calculation of the infiltration and exfiltration air flow to each zone of the building as well as the flows between zones. The system uses miniature permeation tubes as tracer emitters and passive samplers to collect the perfluorocarbon tracers and is, therefore, quite simple and inexpensive to implement. The passive samplers are returned to the laboratory for analysis where the tracers are separated by gas chromatography and quantified by an electron capture detector. A detailed, experimental description of this technique has been presented elsewhere [1].

The ventilation flows are computed by inserting the measured tracer concentrations and the known tracer emission rates into the mass balance and flow balance equations for each zone of the building. In general, for $\mathrm{N}$ well-mixed zones, there are $\mathrm{N}^{2}$ mass balance and $2 \mathrm{~N}+1$ air flow balance equations to solve in calculating the ventilation quantities of interest. It can be shown that the tracer mass balance equations and the air flow balance 
equations can be combined into the following single matrix equation for the general N-zone case:

$$
\left[\begin{array}{ccccc}
-1 & 1 & 1 & . . & 1 \\
0 & \mathrm{C}_{11} & \mathrm{C}_{12} & . . & \mathrm{C}_{1 \mathrm{~N}} \\
0 & \mathrm{C}_{21} & \mathrm{C}_{22} & . . & \mathrm{C}_{2 \mathrm{~N}} \\
: & : & : & & : \\
0 & \mathrm{C}_{\mathrm{N} 1} & \mathrm{C}_{\mathrm{N} 2} & . . & \mathrm{C}_{\mathrm{NN}}
\end{array}\right]\left[\begin{array}{ccccc}
\mathrm{R}_{00} & \mathrm{R}_{01} & \mathrm{R}_{02} & . . & \mathrm{R}_{0 \mathrm{~N}} \\
\mathrm{R}_{10} & \mathrm{R}_{11} & -\mathrm{R}_{12} & . . & -\mathrm{R}_{1 \mathrm{~N}} \\
\mathrm{R}_{20} & -\mathrm{R}_{21} & \mathrm{R}_{22} & . . & -\mathrm{R}_{2 \mathrm{~N}} \\
: & : & : & & : \\
\mathrm{R}_{\mathrm{N} 0} & -\mathrm{R}_{\mathrm{N} 1} & -\mathrm{R}_{\mathrm{N} 2} & . . & \mathrm{R}_{\mathrm{NN}}
\end{array}\right]=\left[\begin{array}{ccccc}
0 & 0 & 0 & . . & 0 \\
\mathrm{~S}_{1} & \mathrm{~S}_{1} & 0 & . . & 0 \\
\mathrm{~S}_{2} & 0 & \mathrm{~S}_{2} & . . & 0 \\
: & : & : & & : \\
\mathrm{S}_{\mathrm{N}} & 0 & 0 & . . & \mathrm{S}_{\mathrm{N}}
\end{array}\right]
$$

where $\quad R_{i j}=$ rate of air flow from zone $i$ to zone $j(i \neq j$; zone $0=$ outdoors).

$R_{i i}=$ sum of all air flows into or out of zone $i(i \geq 1)$.

$R_{00}=$ sum of all infiltration flows $=\Sigma R_{0 i}$

$\mathrm{C}_{\mathrm{ij}}=$ concentration of tracer $\mathrm{i}$ in zone $\mathrm{j}\left(\mathrm{C}_{\mathrm{i} 0}=0\right)$.

$\mathrm{S}_{\mathrm{j}}=$ source emission rate of the tracer in zone $\mathrm{j}$ (constant).

Using boldface to denote matrices, the above matrix equation can be written as $\mathbf{C R}=\mathbf{S}$.

A first order error analysis routine has been developed which computes error estimates for the calculated ventilation flows. These error estimates can be written in matrix form as:

$$
\Delta \mathbf{R}=\left[\left(\mathbf{C}^{-1}\right)^{2}\left(\Delta \mathbf{S}^{2}+\Delta \mathbf{C}^{2} \mathbf{R}^{2}\right)\right]^{1 / 2}
$$

where $\Delta \mathbf{R}=$ matrix of ventilation flow errors (e.g. $\Delta R_{00}=$ error in the total infiltration flow $\mathrm{R}_{00}$ ),

$\Delta \mathbf{S}=$ matrix of estimated source emission rate errors, $\Delta \mathbf{C}=$ matrix of estimated tracer concentration errors, and $\mathbf{C}^{-1}=$ inverse of the concentration matrix.

A published paper which describes the above computations in more detail and provides example calculations is available [2]. 


\section{Creating the Database}

The following tasks were required to create the PFT database: 1 ) implementing an automated zone reduction procedure, 2) implementing a procedure for calculating flow ratios and their errors, 3) other programming changes, 4) recomputing the ventilation flows and errors for all of the homes, and 5) entering additional information into the database that did not previously exist on a computerized format.

\section{Zone Reduction}

When one unknowingly divides a well-mixed zone into two separate zones, the computational solution for the ventilation flows becomes very unstable. In the mathematical literature, the system is termed illconditioned. Fortunately, there is a way to reliably detect such an unstable situation. The method involves using the matrix of tracer concentrations to compute a condition number $=\mathrm{K}(\mathrm{C})$. Prior work has indicated that unstable solutions result when the normalized condition number $=$ $\mathrm{K}(\mathrm{C}) / \mathrm{N}^{3 / 2}>2$ where $\mathrm{N}$ is the number of building zones [2].

Through the use of the condition number, large flow errors for homes with two or more well-mixed zones can be eliminated by combining the well-mixed zones into a single zone prior to the computations. The resulting flows will be accompanied by much smaller error estimates. This work involved the necessary programming to identify unstable solutions, select the appropriate zones to be combined, and rework the flow computations.

Home ventilation measurements that have been recomputed by the automatic zone reduction procedure can be identified by their file code. Normally the file code is five characters. When the zone reduction procedure has been applied, two additional characters are added to the code. The first additional character is a number which indicates the number of zone reductions. The second character is either an "A" or an "S". The "S" means that one tracer was Selected and used for the combined zone while the "A" means that the two tracers emitted in the zones being reduced were Added together and used as if they were a single tracer.

For example, if a four zone house with the file code 1077D has the zone reduction procedure applied to it (making it a three zone house) and a selected tracer was used, a new house measurement set will be created with the file code 1077D1S. If the zone reduction procedure is applied a second time (the three zone house is reduced to a two zone) and the tracers are added, a new measurement set is created with the file code 1077D2A. The original sets are not deleted if the zone reduction procedure is applied. Therefore, in the above example, there will be three sets of calculations all of which apply to the same house measurement. 


\section{Flow Ratios and Their Errors}

An error analysis procedure for the ratios of selected house flows has been implemented in the database. Although the ratios of the ventilation flows are easily computed, the error estimate on the ratio is not simply a functions of the error estimates on the individual flows. This is because the ventilation flows all depend on the same set of tracer concentrations and, therefore, are not independent of each other.

The error analysis technique used for the flow ratios is a first order technique similar to that used in computing error estimates on the individual flows [2]. Only paired sets of flows have had their ratios and errors computed. For example the ratio of $R_{12} / R_{21}$ has been computed but not $R_{12} / R_{31}$. Although not requested, the ratios of the zonal infiltration rates to the exfiltration rates and their associated errors have also been computed and included in the database.

\section{Other Programming Changes}

These changes include an output procedure which writes the results to a file compatible with most database programs, streamlining of the program code to run a large number of computations in a minimum time period, and changes necessary to accommodate old file formats to our current calculational program.

\section{Flow Recomputations}

Some 2100 sets of house flows and error have been recomputed for this project starting from the measured tracer emission rates and concentrations. Approximately $15 \%$ of the recomputations occurred because of the automatic zone reduction procedure described in the previous section.

The system used for the recomputations is now ready and available for Phase II of this project. This phase will approximately double the size of the existing database and further diversify the geographic distribution of the measurement set.

\section{Additional Information}

Two important sets of additional information were added to the database. First, a description of the house structure was included in a specially designed house setup code. This code indicates where each house zone is located, the floor divisions, where the kitchen and bedrooms in the house are located, if the house has a fireplace, and whether the house contains a basement, crawl space, attic or garage as part of the measured space. With a little practice, the house setup code can be used to both visualize the physical structure of the house and recreate the method used to measure house ventilation. 
1) dashes are used to separate floors,

2) zone numbers are written from the bottom of the house to the top,

3) the following codes are used:

$$
\begin{array}{ll}
B=\text { Basement } & C=\text { Crawl Space } \\
\mathrm{K}=\text { Kitchen } & \mathrm{G}=\text { Garage } \\
\mathrm{R}=\text { Bedroom } & \mathrm{A}=\text { Attic } \\
\mathrm{F}=\text { Fireplace } & \mathrm{S}=\text { Split Level }
\end{array}
$$

4) the above codes are used after the zone in which they exit with the exception of the "S" and "F" which occur at the beginning of the code. setup code.

The examples below should help to clarify the use of the house

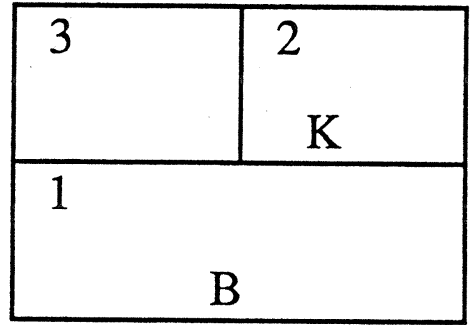

$1 \mathrm{~B}-2 \mathrm{~K} 3$

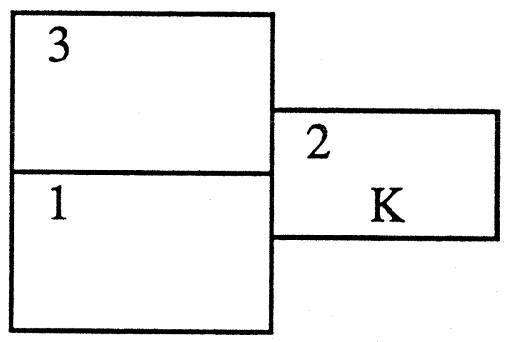

S1-2K-3

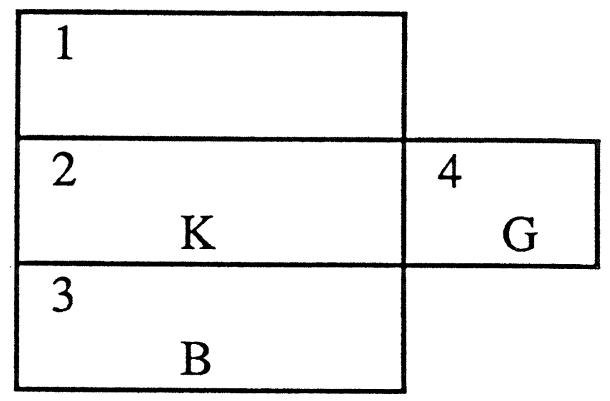

3B-2K $4 \mathrm{G}-1$

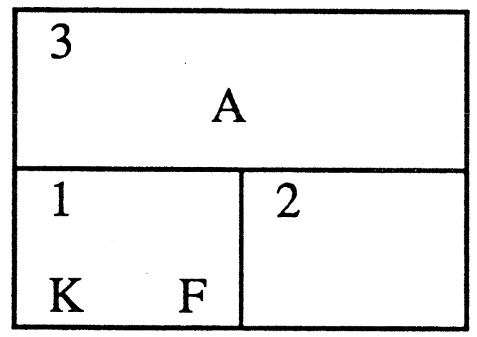

F1K2-3A

The second major addition to the database that did not already exist on a computerized format is information about the projects for which the ventilation measurements were made. For the work done to date, there were about 40 separate projects. This means, on average, that each project comprised approximately 50 house measurements.

A group of ventilation measurements were associated with a particular project name if they all were conducted by the same institution and if all the homes were located in the same geographic area, i.e. within about 100 miles of each other. This type of division will make it relatively 
easy to obtain wind and temperature information for each of the homes in the database if that is desired at a later date.

Each project has a unique project code, a full description of the location of the homes and a short description of the project. In addition, there is information about the institution that made the measurements such as the names and phone numbers of two contact people at the institution as well as a full address for the contact people. 


\section{Structure of the Database}

This section outlines the files associated with the PFT database and, within each file, the fields and their descriptions. The information contained herein should be sufficient to create a database structure in virtually any commercial database program. However, the structure was specifically geared towards two popular database programs: DBASE III Plus, which is available on the IBM PC and PS/2 family of computers and Omnis III Plus, which runs on the Macintosh line of computers available from Apple Computer.

The database consists of six distinct files:

1) the Project file, which contains information about the institution which performed the measurements and the locations of the houses associated with the project,

2) the House file, which contains information associated with the entire house such as the house setup code, the start and stop dates for the measurement and the overall air exchange rate,

3) the Zone 1 file, which contains information unique to the first house zone in the measured building including the zone volume, the tracer used and the infiltration and exfiltration flow rates for the zone,

4) the Zone 2 file, which contains information unique to the second house zone, if any,

5) the Zone 3 file, which contains information unique to the third house zone, if any, and

6) the Zone 4 file, which contains information unique to the fourth house zone, if any.

There are many house records associated with a particular project record, i.e. there is a many-to-one relationship between the Project file and the House file. Each House record is associated with one Zone 1 record since each house must have at least one zone. Therefore, a one-to-one relationship exists between the House file and the Zone 1 file. In addition, each House record may or may not be associated with a record from the Zone 2, Zone 3 or Zone 4 files depending on how many zones the house was divided into for the ventilation measurement.

The files associated with the PFT database and the connections between them can be illustrated using the diagram shown on the next page. 


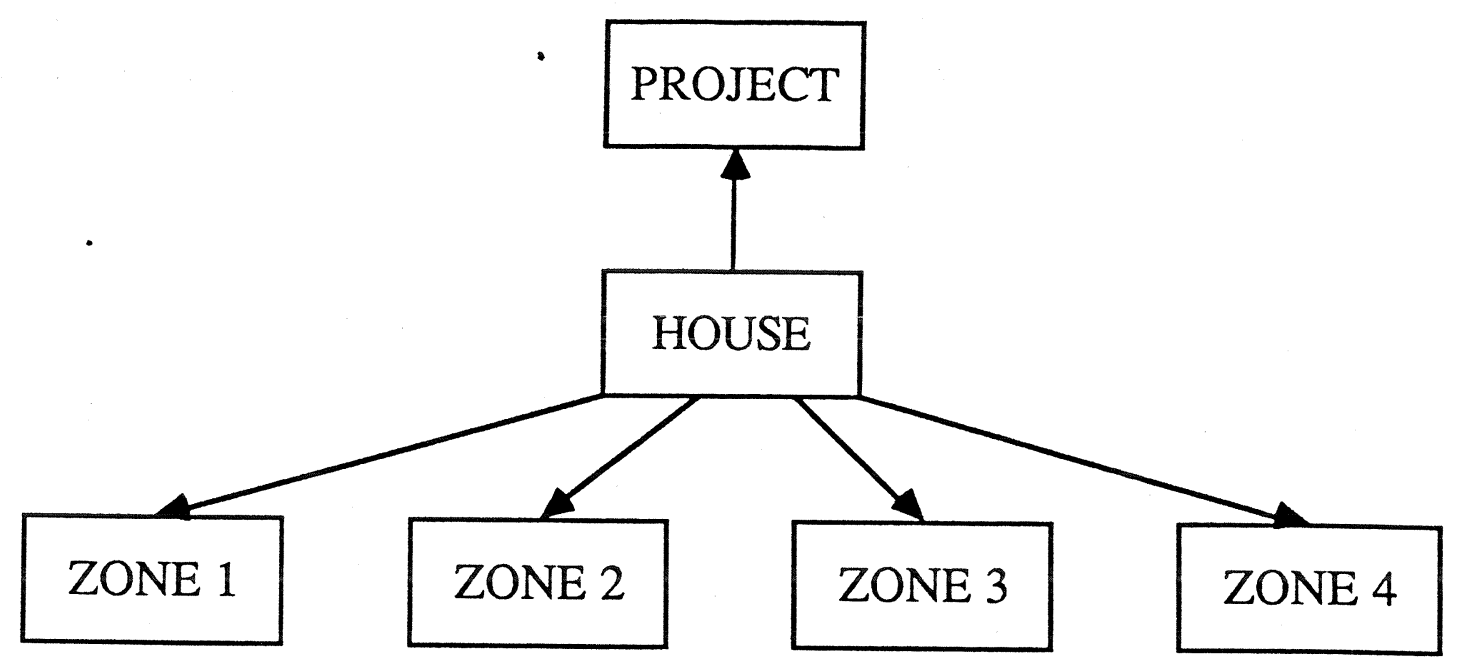

Each house calculation can be identified by a unique field that exists in the House file and all its associated zone files. In the description of the fields in each file below, this field is labelled HOFILE in the House file, Z1FILE in the Zone 1 file, Z2FILE in the Zone 2 file, Z3FILE in the Zone 3 file and $\mathrm{Z} 4 \mathrm{FILE}$ in the Zone 4 file. The House and Zone files can always be related through this unique file code.

The following pages contain a detailed description of the fields associated with each of the files in the database. Included are the field type (character, number or date), the length of the character fields, the number of decimal places in the number fields and a description of the contents of each field. 


\begin{tabular}{|c|c|c|c|c|}
\hline & NAME & TYPE & LENGTH & DESCRIPTION \\
\hline 1 & PRCODE & Char & 10 & A UNIQUE PROJECT CODE \\
\hline 2 & PRZIP & Char & 8 & ZIP CD. WHERE HOUSES LOCATED \\
\hline 3 & PRSTATE & Char & 2 & STATE WHERE HOUSES LOCATED \\
\hline 4 & PRCNTRY & Char & 10 & COUNTRY WHERE HOUSES LOCATED \\
\hline 5 & PRDESC1 & Char & 40 & 1ST LINE OE PROJECT DESCRIPT. \\
\hline 6 & PRDESC2 & Char & 40 & 2ND LINE OF PROJECT DESCRIPT. \\
\hline 7 & PRCONT 1 & Char & 30 & CONTACT 1 \\
\hline 8 & PRCONT2 & Char & 30 & CONTACT 2 \\
\hline 9 & PRTEL1 & Char & 12 & TELEPHONE NUMBER 1 \\
\hline 10 & PRTEL2 & Char & 12 & TELEPHONE NUMBER 2 \\
\hline 11 & PRCOMP 1 & Char & 40 & COMPANY NAME 1 \\
\hline 12 & PRCOMP 2 & Char & 40 & COMPANY NAME 2 \\
\hline 13 & PRADDR & Char & 40 & ADDRESS FOR COMPANY \\
\hline 14 & PRCOTWN & Char & 40 & TOWN FOR COMPANY \\
\hline 15 & PRCOST & Char & 2 & STATE FOR COMPANY \\
\hline 16 & PRCOZIP & Char & 7 & ZIP FOR COMPANY \\
\hline 17 & PRTOWN & Char & 40 & TOWN WHERE HOUSES LOCATED \\
\hline
\end{tabular}

FILE STRUCTURE FOR THE HOUSE FILE

\begin{tabular}{|c|c|c|c|c|c|}
\hline & NAME & TYPE & LENGTH & DEC & DESCRIPTION \\
\hline 1 & PRCODE & Char & 10 & & A UNIQUE PROJECT CODE \\
\hline 2 & HOF ILE & Char & 8 & & A UNIQUE HOUSE CODE \\
\hline 3 & HOSETUP & Char & 12 & & THE HOUSE SETUP CODE \\
\hline 4 & HOCODE & Char & 10 & & HOUSE CODE SUPPLIED BY USER \\
\hline 6 & HOZONES & Number & & 0 & NUMBER OF ZONES \\
\hline 5 & HOCOND & Number & & 3 & THE OVERALL CONDITION NUMBER \\
\hline 8 & HODATEI & Date & & & START DATE \\
\hline 7 & HOT IME 1 & Char & 5 & & START TIME \\
\hline 9 & HODATE2 & Date & & & STOP DATE \\
\hline 10 & HOT IME 2 & Char & 5 & & STOP TIME \\
\hline 11 & HOACHT & Number & & 3 & HOUSE ACH \\
\hline 12 & HOEACHT & Number & & 3 & ERROR FOR ABOVE \\
\hline 13 & HORIT & Number & & 1 & TOTAL HOUSE INFILTRATION FLOW \\
\hline 14 & HOERIT & Number & & 1 & ERROR FOR ABOVE \\
\hline 15 & HODATEC & Date & & & DATE RESULTS COMPUTED \\
\hline 16 & HOHRS & Number & & 1 & TOTAL SAMPLE HOURS \\
\hline
\end{tabular}




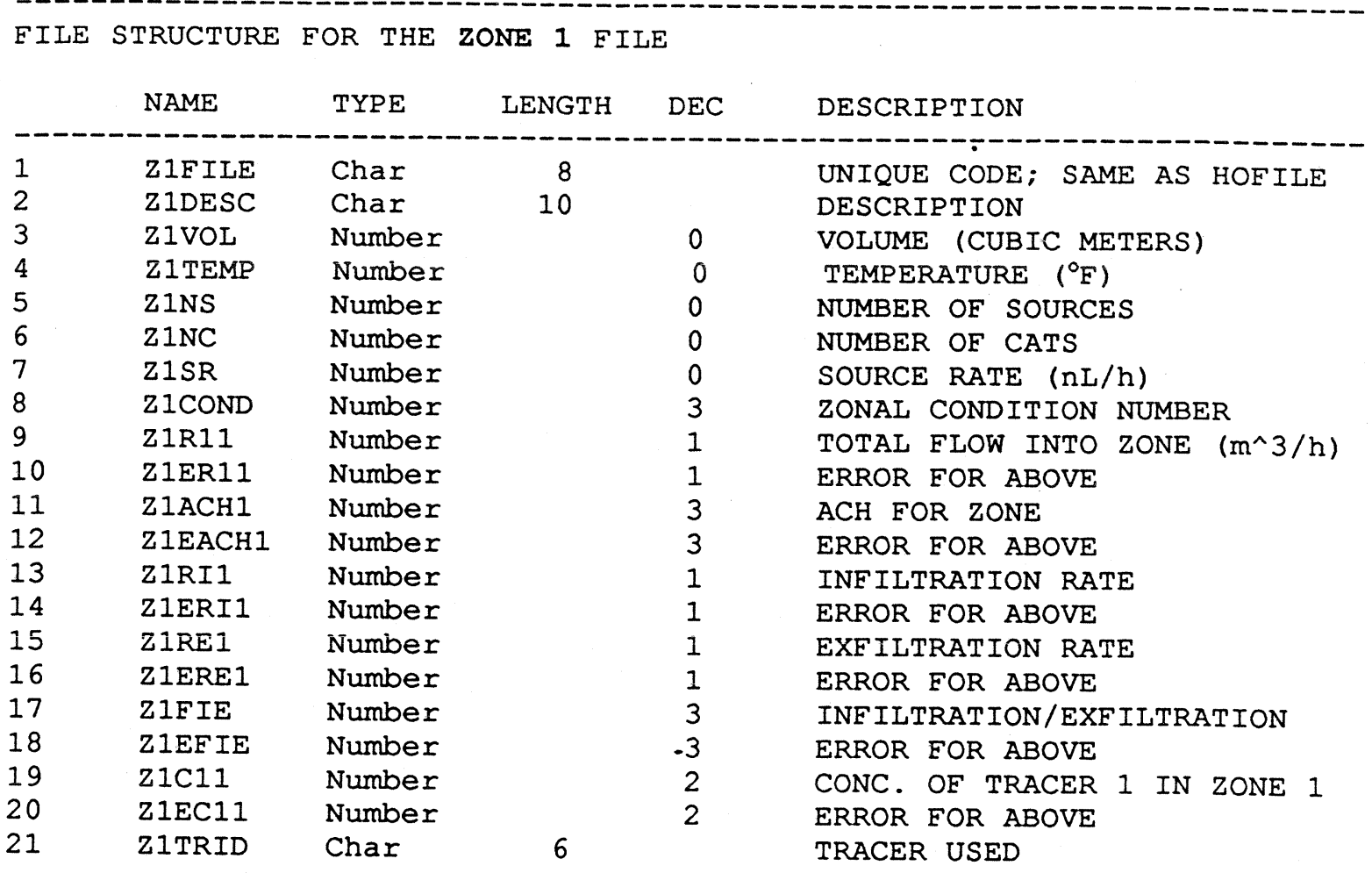


FILE STRUCTURE FOR THE ZONE 2 FILE

\begin{tabular}{|c|c|c|c|c|c|}
\hline & NAME & TYPE & LENGTH & DEC & DESCRIPTION \\
\hline 1 & Z2FILE & Char & 8 & & UNIQUE CODE; SAME AS HOFILE \\
\hline 2 & Z2DESC & Char & 10 & & DESCRIPTION \\
\hline 3 & Z2VOL & Number & & 0 & VOLUME \\
\hline 4 & Z2TEMP & Number & & 0 & TEMPERATURE \\
\hline 5 & Z2NS & Number & & 0 & NUMBER OF SOURCES \\
\hline 6 & $\mathrm{Z} 2 \mathrm{NC}$ & Number & & 0 & NUMBER OF CATS \\
\hline 7 & Z2SR & Number & & 0 & SOURCE RATE \\
\hline 8 & $\mathrm{Z} 2 \mathrm{COND}$ & Number & & 3 & ZONAL CONDITION NUMBER \\
\hline 9 & Z2R22 & Number & & 1 & TOTAL FLOW INTO ZONE \\
\hline 10 & Z2ER22 & Number & & 1 & ERROR FOR ABOVE \\
\hline 11 & $\mathrm{Z} 2 \mathrm{ACH} 2$ & Number & & 3 & ACH FOR ZONE \\
\hline 12 & $\mathrm{Z} 2 \mathrm{EACH} 2$ & Number & & 3 & ERROR FOR ABOVE \\
\hline 13 & Z2RI2 & Number & & 1 & INEILTRATION RATE \\
\hline 14 & Z2ERI2 & Number & & 1 & ERROR FOR ABOVE \\
\hline 15 & Z2RE2 & Number & & 1 & EXFILTRATION RATE \\
\hline 16 & Z2ERE2 & Number & & 1 & ERROR FOR ABOVE \\
\hline 17 & Z2FIE & Number & & 3 & INE ILTRATION/EXFILTRATION \\
\hline 18 & Z2EFIE & Number & & 3 & ERROR FOR ABOVE \\
\hline 19 & $\mathrm{Z} 2 \mathrm{C} 12$ & Number & & 2 & CONC. OF TRACER 1 IN ZONE 2 \\
\hline 20 & $\mathrm{Z} 2 \mathrm{EC} 12$ & Number & & 2 & ERROR FOR ABOVE \\
\hline 21 & $\mathrm{z} 2 \mathrm{C} 21$ & Number & & 2 & CONC. OF TRACER 2 IN ZONE 1 \\
\hline 22 & 22EC21 & Number & & 2 & ERROR FOR ABOVE \\
\hline 23 & $\mathrm{z} 2 \mathrm{C} 22$ & Number & & 2 & CONC. OF TRACER 2 IN ZONE 2 \\
\hline 24 & Z2EC22 & Number & & 2 & ERROR FOR ABOVE \\
\hline 25 & Z2R12 & Number & & 1 & FLOW FROM ZONE 1 TO 2 \\
\hline 26 & Z2ER12 & Number & & 1 & ERROR FOR ABOVE \\
\hline 27 & Z2R21 & Number & & 1 & FLOW FROM ZONE 2 TO 1 \\
\hline 28 & Z2ER21 & Number & & 1 & ERROR FOR ABOVE \\
\hline 29 & $\mathrm{Z} 2 \mathrm{~F} 12$ & Number & & 3 & RATIO OF $12 / 21$ \\
\hline 30 & $\mathrm{Z} 2 \mathrm{EF} 12$ & Number & & 3 & ERROR FOR ABOVE \\
\hline 31 & Z2TRID & Char & 6 & & TRACER USED \\
\hline
\end{tabular}




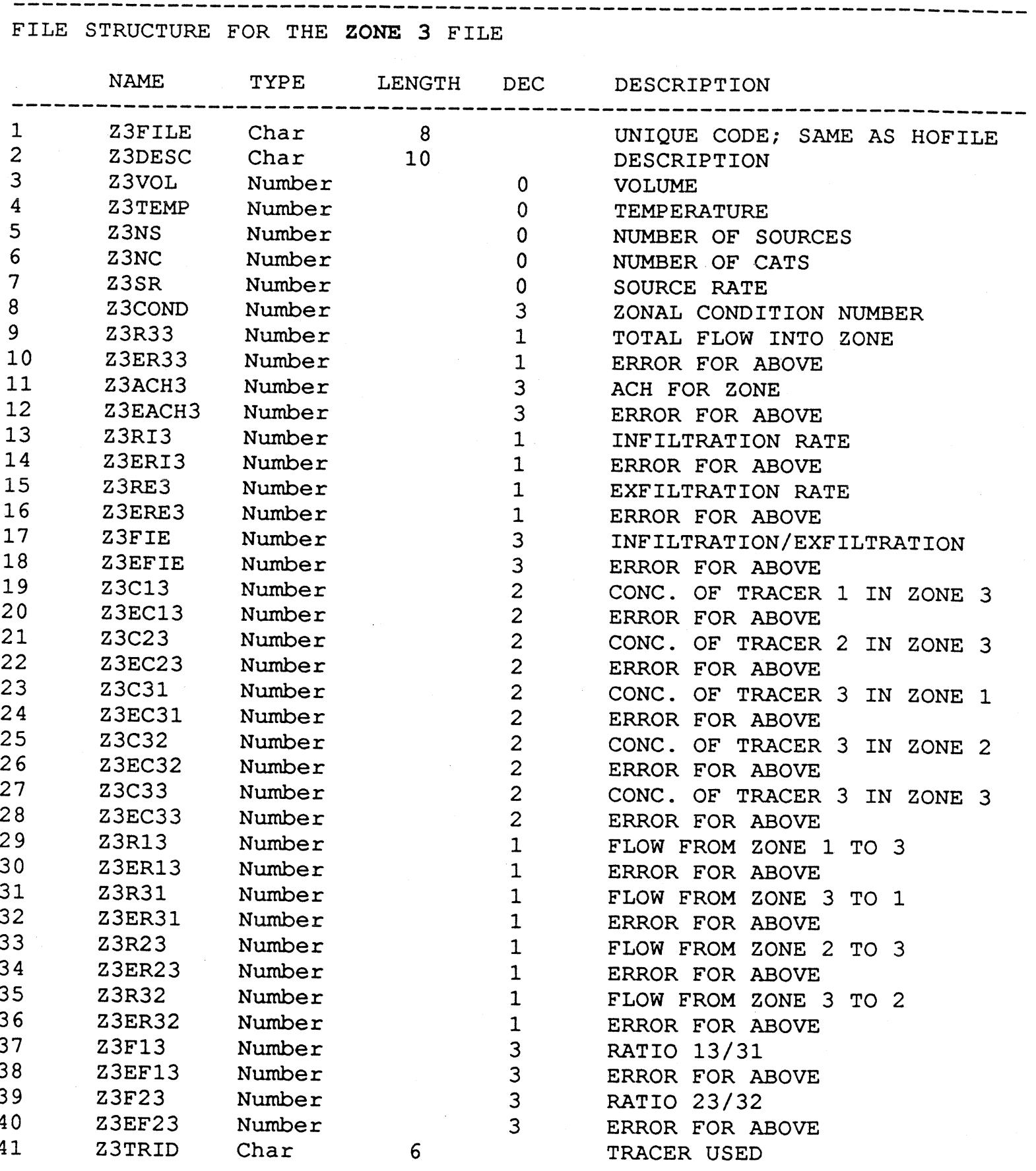


FILE STURCTURE FOR THE ZONE 4 FILE

\begin{tabular}{|c|c|c|c|c|c|c|c|c|}
\hline & NAME & TYPE & LENGTH & $\mathrm{DEC}$ & \multicolumn{4}{|l|}{ DESCRIPTION } \\
\hline 1 & Z4EILE & Char & 8 & & UNIQUE CODE; SAME & $\mathrm{E}$ AS & HOFII & LE \\
\hline 2 & Z 4DESC & Char & 10 & & DESCRIPTION & $\cdot$ & & \\
\hline 3 & Z4VOL & Number & & 0 & VOLUME & & & \\
\hline 4 & Z 4TEMP & Number & & 0 & TEMPERATURE & & & \\
\hline 5 & $\mathrm{Z} 4 \mathrm{NS}$ & Number & & 0 & NUMBER OF SOURCES & & & \\
\hline 6 & $\mathrm{Z} 4 \mathrm{NC}$ & Number & & 0 & NUMBER OF CATS & & & \\
\hline 7 & Z 4SR & Number & & 0 & SOURCE RATE & & & \\
\hline 8 & $\mathrm{Z} 4 \mathrm{COND}$ & Number & & 3 & ZONAL CONDITION $\mathrm{N}$ & NUMBE & ER & \\
\hline 9 & Z 4R44 & Number & & 1 & TOTAL FLOW INTO & ZONE & & \\
\hline 10 & Z 4ER44 & Number & & 1 & ERROR FOR ABOVE & & & \\
\hline 11 & $\mathrm{Z} 4 \mathrm{ACH} 4$ & Number & & 3 & ACH FOR ZONE & & & \\
\hline 12 & $\mathrm{Z} 4 \mathrm{EACH} 4$ & Number & & 3 & ERROR FOR ABOVE & & & \\
\hline 13 & Z 4RI4 & Number & & 1 & INEILTRATION RATE & & & \\
\hline 14 & Z 4ERI 4 & Number & & 1 & ERROR FOR ABOVE & & & \\
\hline 15 & $\mathrm{Z} 4 \mathrm{RE} 4$ & Number & & 1 & EXEILTRATION RATE & & & \\
\hline 16 & Z 4ERE 4 & Number & & 1 & ERROR FOR ABOVE & & & \\
\hline 17 & Z 4FIE & Number & & 3 & INE ILTRATION/EXEI & ILTRA & ATION & \\
\hline 18 & Z 4 EF IE & Number & & 3 & ERROR FOR ABOVE & & & \\
\hline 19 & $\mathrm{Z} 4 \mathrm{C} 14$ & Number & & 2 & CONC. OE TRACER & 1 IN & $\mathrm{ZONE}$ & 4 \\
\hline 20 & $\mathrm{Z} 4 \mathrm{EC} 14$ & Number & & 2 & ERROR FOR ABOVE & & & \\
\hline 21 & $\mathrm{Z} 4 \mathrm{C} 24$ & Number & & 2 & CONC. OF TRACER & 2 IN & $\mathrm{ZONE}$ & 4 \\
\hline 22 & Z 4EC24 & Number & & 2 & ERROR FOR ABOVE & & & \\
\hline 23 & $\mathrm{Z} 4 \mathrm{C} 34$ & Number & & 2 & CONC. OF TRACER 3 & 3 IN & ZONE & 4 \\
\hline 24 & $\mathrm{Z} 4 \mathrm{EC} 34$ & Number & & 2 & ERROR FOR ABOVE & & & \\
\hline 25 & $\mathrm{Z} 4 \mathrm{C} 41$ & Number & & 2 & CONC. OF TRACER & 4 IN & ZONE & 1 \\
\hline 26 & Z 4EC 41 & Number & & 2 & ERROR FOR ABOVE & & & \\
\hline 27 & $\mathrm{Z} 4 \mathrm{C} 42$ & Number & & 2 & CONC. OF TRACER & 4 IN & ZONE & 2 \\
\hline 28 & $\mathrm{Z} 4 \mathrm{EC} 42$ & Number & & 2 & ERROR FOR ABOVE & & & \\
\hline 29 & $\mathrm{Z} 4 \mathrm{C} 43$ & Number & & 2 & CONC. OF TRACER & 4 IN & ZONE & 3 \\
\hline 30 & $\mathrm{Z} 4 \mathrm{EC} 43$ & Number & & 2 & ERROR FOR ABOVE & & & \\
\hline 31 & $\mathrm{Z} 4 \mathrm{C} 44$ & Number & & 2 & CONC. OF TRACER & 4 IN & ZONE & 4 \\
\hline 32 & $\mathrm{Z} 4 \mathrm{EC} 44$ & Number & & 2 & ERROR EOR ABOVE & & & \\
\hline 33 & Z4R14 & Number & & 1 & FLOW FROM ZONE 1 & TO 4 & & \\
\hline 34 & Z 4ERI 4 & Number & & 1 & ERROR FOR ABOVE & & & \\
\hline 35 & Z 4R41 & Number & & 1 & FLOW FROM ZONE 4 & TO 1 & & \\
\hline 36 & Z 4ER41 & Number & & 1 & ERROR FOR ABOVE & & & \\
\hline 37 & Z4R24 & Number & & 1 & FLOW FROM ZONE 2 & TO 4 & & \\
\hline 8 & Z 4ER24 & Number & & 1 & ERROR FOR ABOVE & & & \\
\hline 9 & $\mathrm{Z} 4 \mathrm{R} 42$ & Number & & 1 & FLOW FROM ZONE 4 & TO 2 & & \\
\hline 0 & Z 4ER42 & Number & & 1 & ERROR FOR ABOVE & & & \\
\hline 11 & Z 4R34 & Number & & 1 & FLOW FROM ZONE 3 & TO 4 & & \\
\hline 12 & Z 4ER34 & Number & & 1 & ERROR FOR ABOVE & & & \\
\hline 13 & $\mathrm{Z} 4 \mathrm{R} 43$ & Number & & 1 & FLOW FROM ZONE 4 & TO 3 & & \\
\hline 4 & Z 4ER43 & Number & & 1 & ERROR FOR ABOVE & & & \\
\hline 5 & $\mathrm{Z} 4 \mathrm{~F} 14$ & Number & & 3 & RATIO $14 / 41$ & & & \\
\hline 6 & $\mathrm{Z} 4 \mathrm{EF} 14$ & Number & & 3 & ERROR FOR ABOVE & & & \\
\hline 7 & $\mathrm{Z} 4 \mathrm{~F} 24$ & Number & & 3 & RATIO 24/42 & & & \\
\hline 8 & Z 4 EF24 & Number & & 3 & ERROR FOR ABOVE & & & \\
\hline 9 & $\mathrm{Z} 4 \mathrm{~F} 34$ & Number & & 3 & RATIO $34 / 43$ & & & \\
\hline 0 & $\mathrm{Z} 4 \mathrm{EF} 34$ & Number & & 3 & ERROR FOR ABOVE & & & \\
\hline 1 & Z 4TRID & Char & 6 & & TRACER USED & & & \\
\hline
\end{tabular}




\section{Using the Database}

The following section briefly describes the use of the PFT database with DBASE III Plus. This section is not intended to be a manual for using the PFT database with DBASE or is it intended to be a tutorial on the use of DBASE III Plus. We have assumed here that the user is already familiar with DBASE and is looking primarily for general guidelines on creating the database structure and importing the data.

The files contained on the IBM $360 \mathrm{k}$ disks have been written in what is known as comma-delimited format. This means that fields are separated by commas, records are separated by carriage returns, and character fields are surrounded by quotation marks. This is a format that DBASE III Plus can read directly.

Before attempting to read the files, use the CREATE command in DBASE to create a .DBF file for each of the six files described in the previous section. The file formats are listed on the previous five pages. File formats for the Zone files have the HOFILE field renamed Z1FILE, Z2FILE, Z3FILE AND Z4FILE. When creating the .DBF file for each of the Zone files, use HOFILE as the field name. This makes HOFILE the common field link between the House and Zone files. Note also that the common field between the House and Project files is the field called PRCODE.

To import the data into each file, use the APPEND FROM command and identify the file as DELIMITED. Once these files have been imported into their respective .DBF files, the House and Zone files can be related through the field HOFILE in a chain format as required by DBASE. The Project and House files can be related through PRCODE in the same way. To use all six files simultaneously, relate the House and Zone files in the above fashion and use the Project file as a lookup file using PRCODE as the lookup field. This will require a small amount of programming.

The PFT database can also be used on the Apple Macintosh through the Omnis 3 Plus database program. A database structure and a method for viewing the database have already been created for this purpose at BNL. 


\section{References}

1. Dietz, R.N., Goodrich, R.W., Cote, E.A., and Wieser, R.F., "Detailed Description and Performance of a Passive Perfluorocarbon Tracer System for Building Ventilation and Air Exchange Measurements," Measured Air Leakage of Buildings, ASTM STP 904, p. 203-64, American Society for Testing and Materials, Philadelphia (1986).

2. D'Ottavio, T.W., Senum, G.I., and Dietz, R.N., "Error Analysis Techniques for Perfluorocarbon Tracer Derived Multizone Ventilation Rates", Building and Environment, Vol. 23, No. 4 (1988). 